\title{
Extremely Sensitive Microwave Sensor for Evaluation of Dielectric Characteristics of Low-Permittivity Materials
}

\author{
Tanveerul Haq $^{1}{ }^{(\mathbb{D}}$, Cunjun Ruan ${ }^{1,2, * \mathbb{D}}$, Xingyun Zhang ${ }^{1}$, Shahid Ullah ${ }^{1}{ }^{\mathbb{D}}$, \\ Ayesha Kosar Fahad ${ }^{1}$ (1) and Wenlong $\mathrm{He}^{3}$ \\ 1 School of Electronic and Information Engineering, Beihang University, Beijing 100191, China; \\ tanveerulhaq@buaa.edu.cn (T.H.); luckyzhang@buaa.edu.cn (X.Z.); shahidkhan@buaa.edu.cn (S.U.); \\ ayeshakosar@buaa.edu.cn (A.K.F.) \\ 2 Beijing Key Laboratory for Microwave Sensing and Security Applications, Beihang University, Beijing \\ 100191, China \\ 3 College of Electronics and Information Engineering, Shenzhen University, Guangdong 518060, China; \\ wenlong.he@szu.edu.cn \\ * Correspondence: ruancunjun@buaa.edu.cn; Tel.: +86-135-0120-5336
}

Received: 15 February 2020; Accepted: 25 March 2020; Published: 30 March 2020

\begin{abstract}
In this paper, an extremely sensitive microwave sensor is designed based on a complementary symmetric S shaped resonator (CSSSR) to evaluate dielectric characteristics of low-permittivity material. CSSSR is an artificial structure with strong and enhanced electromagnetic fields, which provides high sensitivity and a new degree of freedom in sensing. Electromagnetic simulation elucidates the effect of real relative permittivity, real relative permeability, dielectric and magnetic loss tangents of the material under test (MUT) on the resonance frequency and notch depth of the sensor. Experiments are performed at room temperature using low-permittivity materials to verify the concept. The proposed design provides differential sensitivity between $102 \%$ to $95 \%$ as the relative permittivity of MUT varies from 2.1 to 3. The percentage error between simulated and measured results is less than $0.5 \%$. The transcendental equation has been established by measuring the change in the resonance frequency of the fabricated sensor due to interaction with the MUT.
\end{abstract}

Keywords: Microwave sensor; CSSSR; permittivity; permeability; material under test; transcendental equation

\section{Introduction}

Microwave sensors have quick response time, wide sensing range, high accuracy, no effect of temperature, and are suitable for any climate, therefore these sensors are widely used in different industries like agriculture [1,2], the biomedical sector [3-6], and electronics [7-10]. Recently microwave sensors based on metamaterial (MTM) and complementary MTM structures have achieved high level of sophistication due to the novel properties of MTM such as negative effective permittivity [11], negative effective permeability [12], negative index of refraction [13,14] and backward wave propagation [15]. Initially, these novel properties were achieved using a split-ring resonator (SRR) [16] and complementary split-ring resonator (CSRR) [17]. Later, these artificial structures were used to design microwave sensors for testing liquids [18-22], measurement of thickness [23-26], relative humidity [27], displacement [28-32], rotation [33-36], strain [37-39], permittivity and permeability [40-42]. The main advantages of SRR- and CSRR-based sensors are the small size with high sensitivity, lower cost with robustness, and high precision. The performance of the planar microwave sensor depends on the resonating structure as well as the hosting transmission line [43-48]. 
In [43], an SRR with a resonance frequency of $0.87 \mathrm{GHz}$ is used to design a differential sensor with a size of $0.1 \lambda_{\mathrm{g}}{ }^{2}$ for liquid characterization and an average sensitivity of $0.91 \%$ is achieved. In [44] a stepped impedance resonator (SIR) loaded with a microstrip transmission line is used to design a differential sensor with a size of $0.046 \lambda_{\mathrm{g}}{ }^{2}$ for comparison of three samples simultaneously, and an average sensitivity of $1.81 \%$ is achieved. In [45], a CSRR with resonance frequency of $1.7 \mathrm{GHz}$ is utilized to design a differential sensor with a size of $0.098 \lambda_{\mathrm{g}}{ }^{2}$ for dielectric characterization and the average sensitivity of $1.96 \%$ is achieved. In [46], an SRR loaded with a microstrip transmission line is used to design a differential sensor with a size of $0.034 \lambda_{\mathrm{g}}{ }^{2}$ for comparison of dielectric samples and an average sensitivity of $3.4 \%$ is achieved. In [47], an SIR with resonance frequency $6.1 \mathrm{GHz}$ is used to design a differential sensor with a size of $0.15 \lambda_{\mathrm{g}}{ }^{2}$ for dielectric characterization and the average sensitivity of $8.8 \%$ is achieved. In [48], a dual notch microwave sensor is designed based on complementary bisymmetric SRR with a size of $0.05 \lambda_{\mathrm{g}}{ }^{2}$ for evaluation of dielectric substrates and an average sensitivity of $29.9 \%$ is achieved. The aforementioned sensors are based on permittivity perturbation of MUT and have sensitivity limitations due to small resonance frequency. Two parameters are important for sensitivity comparison, the first being the shift in resonance frequency of the sensor due to interaction with MUT with respect to the free space resonance frequency, and second being the relative permittivity of MUT. The sensitivity of various state of art sensors [49-54] based on the resonance frequency shift is tabulated in Table 1.

Table 1. Comparison of frequency shift with various state of art sensors.

\begin{tabular}{ccccc}
\hline \multirow{2}{*}{ Ref } & Hosting Transmission Line & Resonating Structure & $\begin{array}{c}\text { Frequency Band } \\
\text { (GHz) }\end{array}$ & $\begin{array}{c}\text { Shift in Resonance } \\
\text { Frequency }\end{array}$ \\
\hline$[49]$ & Microstrip & Rectangular CSRR & $0.8-1.3$ & $38 \%$ \\
{$[50]$} & Microstrip & Rectangular CSRR & $1.8-2.8$ & $36 \%$ \\
{$[51]$} & Microstrip & Single Compound CSRR & $1.08-1.63$ & $34 \%$ \\
{$[52]$} & Microstrip & Circular CSRR & $1.75-2.75$ & $36 \%$ \\
{$[53]$} & Microstrip & Hexagonal CSRR & $5.23-8.45$ & $38 \%$ \\
{$[54]$} & Microstrip & Single CSRR & $0.90-10.90$ & $50 \%$ \\
This Work & Microstrip & CSSSR & $13.28-15.17$ & $100 \%$ \\
\hline
\end{tabular}

If two sensors are loaded with identical MUTs then the sensor with high resonance frequency will give higher shift in resonance frequency. Therefore, we have designed a sensor based on a complementary symmetric S-shaped resonator (CSSSR), which provides free space resonance frequency of $15.17 \mathrm{GHz}$. The CSSSR is a negative image of an S-shaped resonator, which has already been used as an end reflector [55], bandpass filter [56], dual-band filter [57], waveguide filter [58], tunable metamaterial [59], and angular velocity sensor [60]. In this work, the CSSSR is coupled with a microstrip transmission line to design a sensor to test the low permittivity materials. The change in resonance frequency and notch depth of the sensor is calculated numerically by permittivity perturbation, permeability perturbation, dielectric loss and magnetic loss perturbation in Section 2. After fabrication, the sensor is tested for sensing low permittivity dielectric material using a vector network analyzer (VNA) and the measured results are formulated in Section 3 and concluded in Section 4.

\section{Design and Simulation of Proposed Sensor}

The design of the proposed sensor is based on a microstrip transmission line which is directly coupled to the CSSSR as shown in Figure 1a. For proper excitation of resonating structure, the microstrip transmission line $(3 \mathrm{~mm})$ and the CSSSR are printed on the top and bottom layer of the substrate as shown in Figure 1b,c respectively. The CSSSR structure is equivalent to parallel combination of resistance $(R c)$, inductance $(L c)$ and capacitance $(C c)$. The microstrip transmission line is equivalent to the inductance $(L)$ and the thickness of the substrate provides the capacitance $(C)$ between the transmission line and the CSSSR. The equivalent lumped element circuit model of the coupled structure 
is shown in Figure 1d, the resonance frequency of the equivalent circuit can be calculated using the following relation [61]:

$$
f_{r}=\frac{1}{2 \pi \sqrt{L_{c}\left(C+C_{c}\right)}}
$$

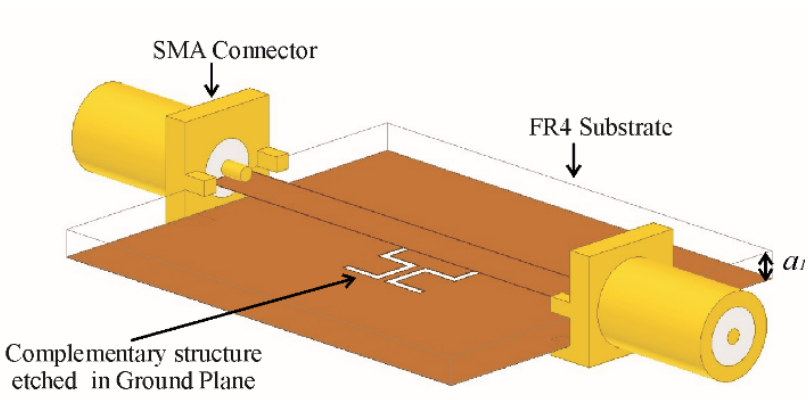

(a) Dimetric View

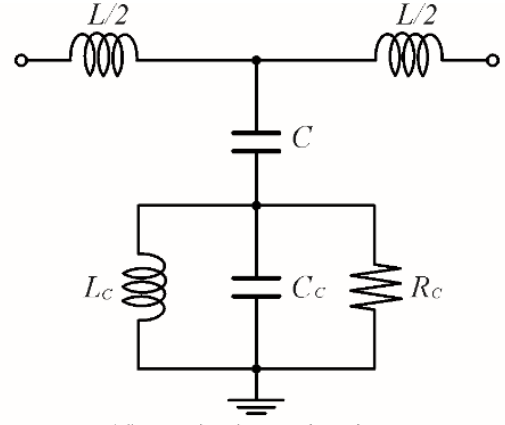

(d) Equivalent Circuit



(b) Top View

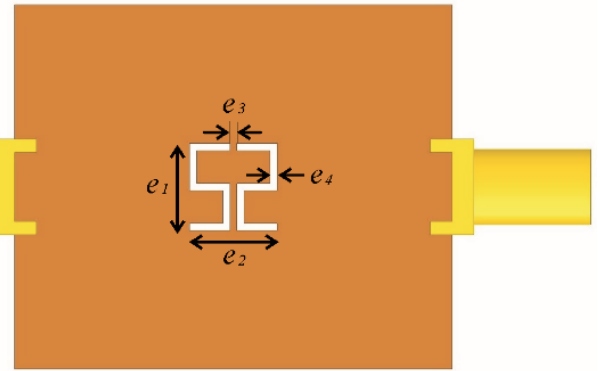

(c) Bottom View

Figure 1. (a) Sensor design based on FR4 epoxy substrate $\left(a_{1}=1.6 \mathrm{~mm}\right)$. (b) Top view of sensor $\left(b_{1}=25 \mathrm{~mm}, b_{2}=30 \mathrm{~mm}, b_{3}=3 \mathrm{~mm}\right)$. (c) Bottom view of sensor $\left(e_{1}=\mathrm{e}_{2}=6 \mathrm{~mm}, e_{3}=\mathrm{e}_{4}=0.5\right.$ $\mathrm{mm}$ ). (d) Equivalent circuit model with $\mathrm{L}$ and $\mathrm{C}$ for the unit length inductance and capacitance of the microstrip transmission line respectively and $(\mathrm{RLC})_{\mathrm{C}}$ for the complementary symmetric S-shaped resonator (CSSSR).

The 3D model of the proposed sensor is simulated in ANSYS HFSS software with the simulation conditions given in ref. [58]. The proposed sensor shows a resonance at $15.17 \mathrm{GHz}$ with notch depth of $-39.84 \mathrm{~dB}$ as shown in Figure 2. The unloaded quality factor of the proposed sensor is 505 which can be calculated by the following relation [62]:

$$
Q=\frac{f_{r}}{\Delta f_{3 d B}}
$$

The resonance frequency of the proposed sensor can be shifted to lower frequencies due to interaction with the material under test (MUT) which is the basic principle of microwave sensors. At the resonance frequency of the CSSSR, the stored electric field $\left(E_{0}\right)$ and magnetic field $\left(H_{0}\right)$ are equal to each other. When a MUT interacts with the CSSSR, it disrupts the equilibrium of the stored electromagnetic fields and generates the new electric field $\left(E_{1}\right)$ and magnetic field $\left(H_{1}\right)$ which causes it to change the resonance frequency. This change in resonance frequency $\left(\Delta f_{r}\right)$ depends on the change in permittivity $(\Delta \varepsilon)$, permeability $(\Delta \mu)$ and volume $(v)$ of the MUT, which can be expressed mathematically as given in reference [63]:

$$
\frac{\Delta f_{r}}{f_{r}}=\frac{\int_{v}\left(\Delta \varepsilon E_{1} \cdot E_{0}+\Delta \mu H_{1} \cdot H_{0}\right) d v}{\int_{v}\left(\varepsilon_{0}\left|E_{0}\right|^{2}+\mu_{0}\left|H_{0}\right|^{2}\right) d v}
$$






Figure 2. Simulated reflection $\left(\mathrm{S}_{11}\right)$ and transmission $\left(\mathrm{S}_{21}\right)$ coefficient of the proposed sensor based on CSSSR. The proposed sensor shows resonance at $15.17 \mathrm{GHz}$ with notch depth $-39.84 \mathrm{~dB}$.

The magnitude of the electric field elucidates the most sensitive region of the sensor, which is plotted in Figure 3. To check the sensitivity of the proposed sensor, MUT is placed at the CSSSR with constant dimensions $\left(d_{1}=10 \mathrm{~mm}, d_{2}=10 \mathrm{~mm}, d_{3}=1 \mathrm{~mm}\right)$ and an air gap of $35 \mu \mathrm{m}$ that is equal to the thickness of the copper layer etched out in the ground plane as shown in Figure 4. For microwave materials, the complex permittivity $\varepsilon$ and permeability $\mu$ can be express by the following relations [63]:

$$
\begin{gathered}
\varepsilon=\varepsilon^{\prime}-j \varepsilon^{\prime \prime}=\varepsilon^{\prime}\left(1-j \tan \delta_{e}\right) \\
\mu=\mu^{\prime}-j \mu^{\prime \prime}=\mu^{\prime}\left(1-j \tan \delta_{m}\right)
\end{gathered}
$$

where $\varepsilon^{\prime}$ and $\varepsilon^{\prime \prime}$ are real and imaginary parts of complex permittivity respectively. $\mu^{\prime}$ and $\mu^{\prime \prime}$ are real and imaginary parts of complex permeability, respectively. $\tan \delta_{e}$ and $\tan \delta_{m}$ are dielectric and magnetic loss tangent, respectively. Natural materials are usually characterized by real relative permittivity $\varepsilon_{r}$ with $\varepsilon^{\prime}=\varepsilon_{r} \varepsilon_{0}$ and real relative permeability with $\mu_{r}$ with $\mu^{\prime}=\mu_{r} \mu_{0}$ at specific frequencies. Now these four parameters $\left(\varepsilon_{r}, \mu_{r}, \tan \delta_{e}, \tan \delta_{m}\right)$ of MUT are used to check the sensitivity of the proposed sensor. The other parameters like langde $\mathrm{G}$ factor $=2$, bulk conductivity $=0$ siemens $/ \mathrm{m}$, magnetic saturation $=$ 0 tesla, mass density $=1.1614 \mathrm{~kg} / \mathrm{m}^{3}$ are the same for all the MUTs. First, $\varepsilon_{r}$ of MUT is varied from 1 to 3 keeping other parameters constant as given in Table 2 and the effect of $\varepsilon_{r}$ on the transmission coefficient of the sensor is plotted in Figure 5. According to simulated results, as $\varepsilon_{r}$ of MUT increases from 1 to 3 , the $f_{0}$ decreases from $15.17 \mathrm{GHz}$ to $13.29 \mathrm{GHz}$ while notch depth increases from $-39.84 \mathrm{~dB}$ to $-42.32 \mathrm{~dB}$. Second, $\mu_{r}$ of MUT is varied from 1 to 3 keeping other parameters constant as given in Table 3 and the effect of $\mu_{r}$ on the transmission coefficient of the sensor is plotted in Figure 6. According to simulated results, as $\mu_{r}$ of MUT increases from 1 to 3 , the $f_{0}$ decreases from $15.17 \mathrm{GHz}$ to $12.80 \mathrm{GHz}$ and notch depth also decreases from $-39.84 \mathrm{~dB}$ to $-32.32 \mathrm{~dB}$. Third, $\tan \delta_{e}$ of MUT is varied from 0 to 0.4 keeping other parameters constant as given in Table 4 and the effect of $\tan \delta_{e}$ on the transmission coefficient of the sensor is plotted in Figure 7. According to simulated results, as $\tan \delta_{e}$ of MUT increases from 0 to 0.4 , the $f_{0}$ increases from $15.17 \mathrm{GHz}$ to $15.28 \mathrm{GHz}$ and notch depth decreases from $-39.84 \mathrm{~dB}$ to -12.96 dB. Fourth, $\tan \delta_{m}$ of MUT is varied from 0 to 0.4 keeping other parameters constant as given in Table 5 and the effect of $\tan \delta_{m}$ on the transmission coefficient of the sensor is plotted in Figure 8. According to 
simulated results, as $\tan \delta_{m}$ of MUT increases from 0 to 0.4 , the $f_{0}$ increases from $15.17 \mathrm{GHz}$ to 15.30 $\mathrm{GHz}$ and notch depth decreases from $-39.84 \mathrm{~dB}$ to $-8.08 \mathrm{~dB}$. These simulated results show that $\varepsilon_{r}$ and $\mu_{r}$ affect the resonance frequency of the sensor as shown in Figure 9. While $\tan \delta_{e}$ and $\tan \delta_{m}$ affect the notch depth of the sensor as shown in Figure 10. However, all these factors do not have the same effect on resonance frequency and notch depth which means that we can distinguish the effect of each factor individually using the proposed sensor.
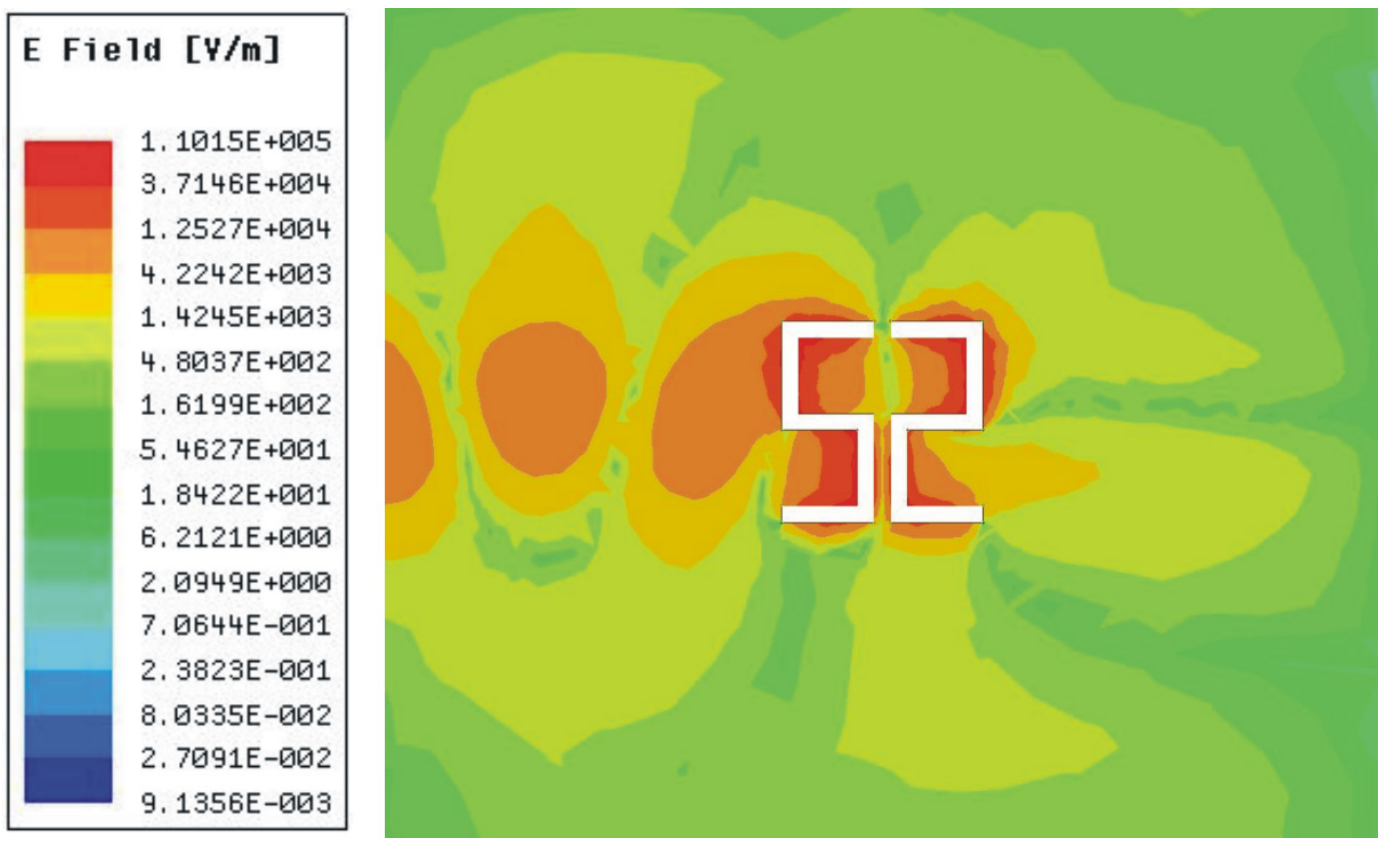

Figure 3. Magnitude of electric field at the resonance frequency of the proposed sensor. The electric field is concentrated at the edges of the CSSSR and its maximum value is $1.10 \times 10^{5} \mathrm{~V} / \mathrm{m}$.

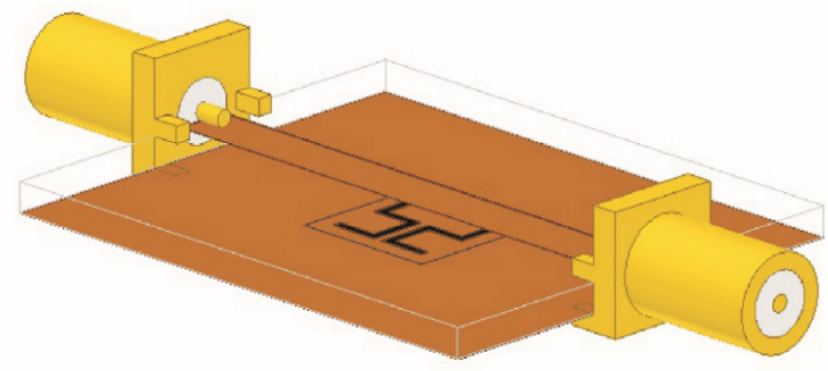

(a) Sensor with MUT

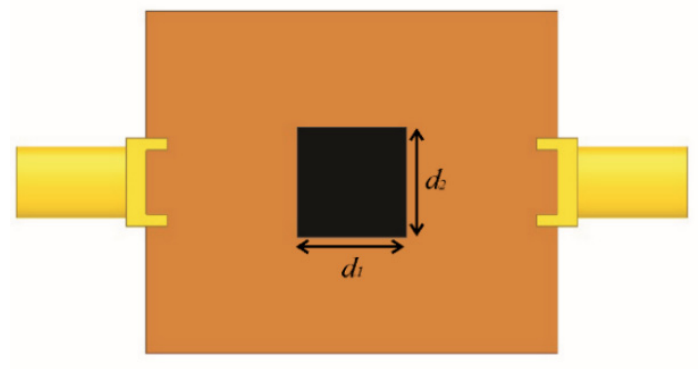

(b) Bottom View

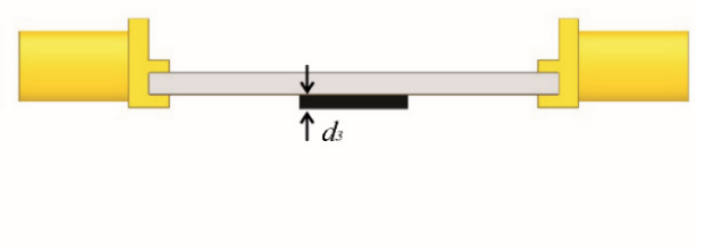

(c) Front View

Figure 4. (a) Sensor based on CSSSR with material under test (MUT) in the ground plane with air gap $(35 \mu \mathrm{m})$. (b) Bottom view of the sensor with MUT $\left(d_{1}=10 \mathrm{~mm}\right.$, and $\left.d_{2}=10 \mathrm{~mm}\right)$. (c) Front view of the sensor with $\operatorname{MUT}\left(d_{3}=1 \mathrm{~mm}\right)$. 
Table 2. Effect of relative permittivity of MUT on resonance frequency and notch depth of the sensor.

\begin{tabular}{cccccc}
\hline & $\begin{array}{c}\text { Material Under Test } \\
\text { (MUT) }\end{array}$ & & Resonance Frequency & Notch Depth \\
\hline$\varepsilon_{\mathbf{r}}$ & $\mu_{\mathbf{r}}$ & $\tan \delta_{\mathbf{e}}$ & $\tan \delta_{\mathbf{m}}$ & $\mathbf{G H z}$ & $\mathbf{d B}$ \\
\hline 1.0 & 1 & 0 & 0 & 15.17 & -39.84 \\
1.5 & 1 & 0 & 0 & 14.57 & -44.88 \\
2.0 & 1 & 0 & 0 & 14.07 & -38.41 \\
2.5 & 1 & 0 & 0 & 13.69 & -40.77 \\
3.0 & 1 & 0 & 0 & 13.29 & -42.32 \\
\hline
\end{tabular}

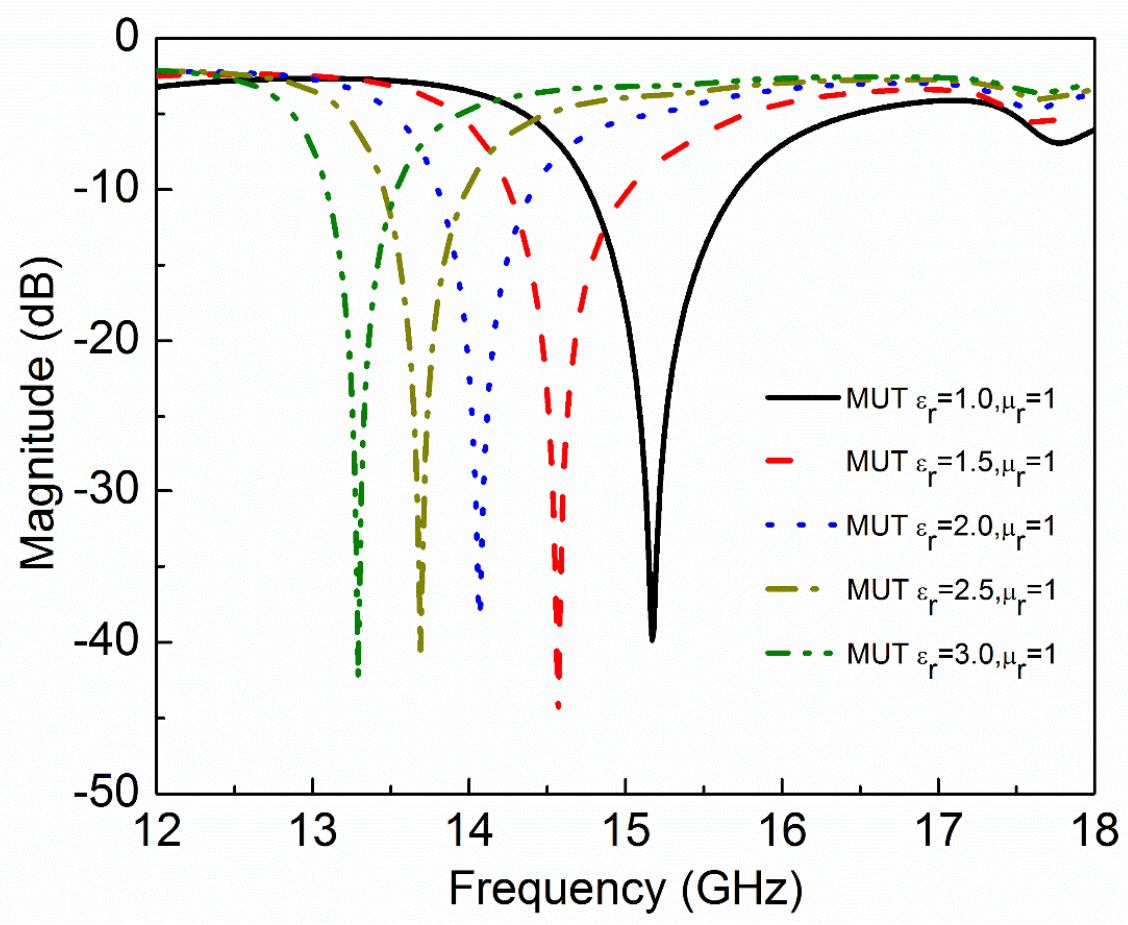

Figure 5. Simulated transmission coefficient $\left(\mathrm{S}_{21}\right)$ of the sensor due to interaction with the MUT with different values of permittivity $\left(\varepsilon_{\mathrm{r}}\right)$. As the relative permittivity of MUT increases, the resonance frequency decreases.

Table 3. Effect of relative permeability of MUT on resonance frequency and notch depth of the sensor.

\begin{tabular}{cccccc}
\hline & $\begin{array}{c}\text { Material Under Test } \\
\text { (MUT) }\end{array}$ & & Resonance Frequency & Notch Depth \\
\hline$\varepsilon_{\mathbf{r}}$ & $\mu_{\mathbf{r}}$ & $\tan \delta_{\mathbf{e}}$ & $\tan \boldsymbol{\delta}_{\mathbf{m}}$ & $\mathbf{G H z}$ & $\mathbf{d B}$ \\
\hline 1 & 1.0 & 0 & 0 & 15.17 & -39.84 \\
1 & 1.5 & 0 & 0 & 14.01 & -40.11 \\
1 & 2.0 & 0 & 0 & 13.39 & -37.41 \\
1 & 2.5 & 0 & 0 & 13.05 & -37.93 \\
1 & 3.0 & 0 & 0 & 12.80 & -32.23 \\
\hline
\end{tabular}




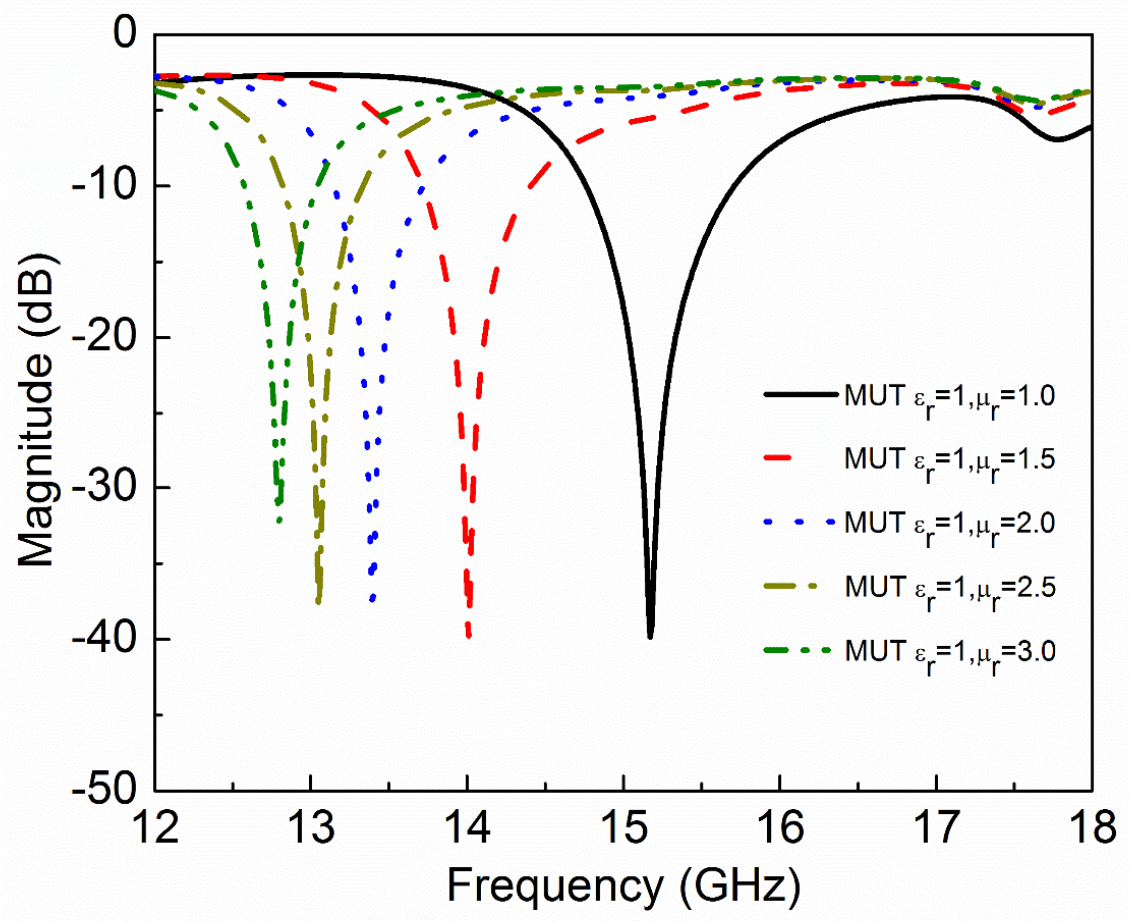

Figure 6. Simulated transmission coefficient $\left(\mathrm{S}_{21}\right)$ of the sensor due to interaction with the MUT with different values of permeability $\left(\mu_{\mathrm{r}}\right)$. As the relative permeability of MUT increases, the resonance frequency decreases.

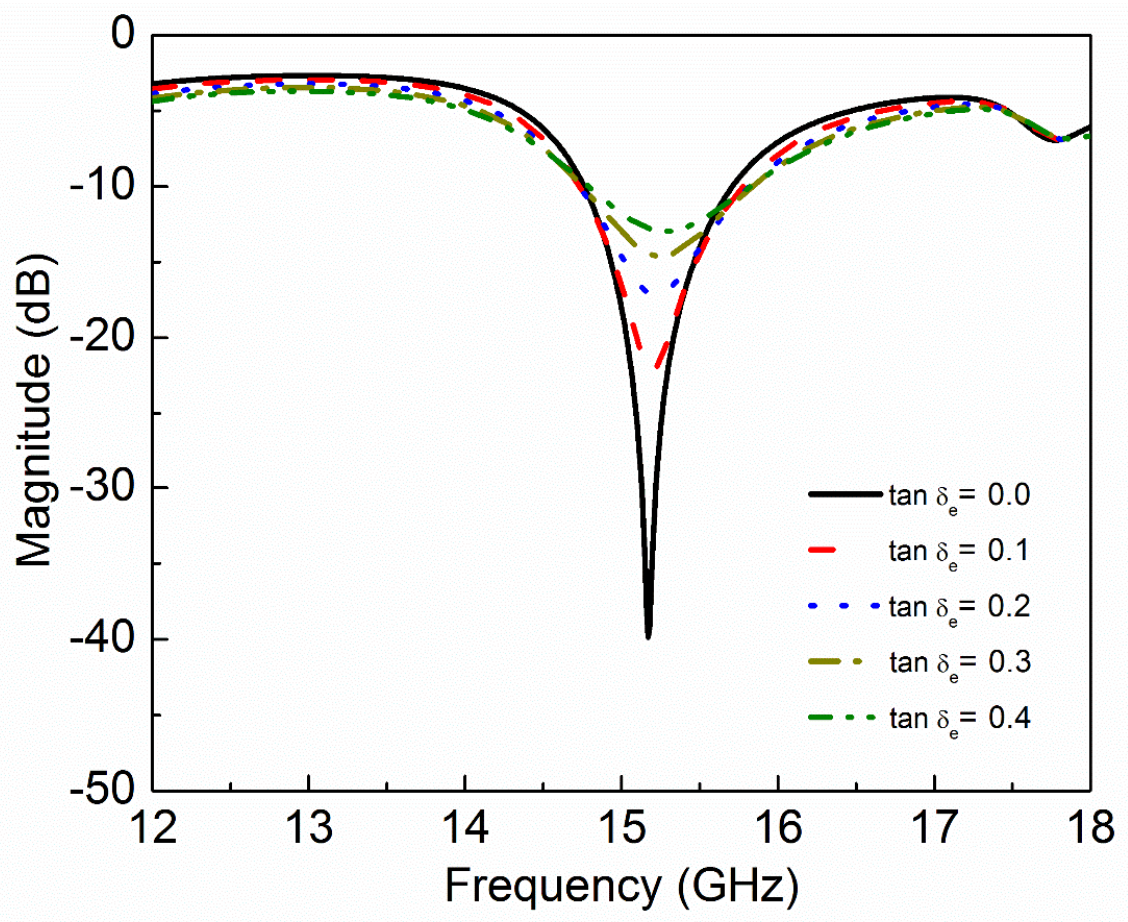

Figure 7. Simulated transmission coefficient $\left(S_{21}\right)$ of the sensor due to interaction with the MUT with different values of dielectric loss tangent $\left(\tan \delta_{\mathrm{e}}\right)$. 
Table 4. Effect of dielectric loss tangent of MUT on resonance frequency and notch depth of the sensor.

\begin{tabular}{cccccc}
\hline & $\begin{array}{c}\text { Material Under Test } \\
\text { (MUT) }\end{array}$ & & Resonance Frequency & Notch Depth \\
\hline$\varepsilon_{\mathbf{r}}$ & $\mu_{\mathbf{r}}$ & $\tan \delta_{\mathbf{e}}$ & $\tan \delta_{\mathbf{m}}$ & $\mathbf{G H z}$ & $\mathbf{d B}$ \\
\hline 1 & 1 & 0.0 & 0 & 15.17 & -39.84 \\
1 & 1 & 0.1 & 0 & 15.20 & -22.15 \\
1 & 1 & 0.2 & 0 & 15.22 & -17.21 \\
1 & 1 & 0.3 & 0 & 15.25 & -14.60 \\
1 & 1 & 0.4 & 0 & 15.28 & -12.96 \\
\hline
\end{tabular}

Table 5. Effect of magnetic loss tangent of MUT on resonance frequency and notch depth of the sensor.

\begin{tabular}{cccccc}
\hline & $\begin{array}{c}\text { Material Under Test } \\
\text { (MUT) }\end{array}$ & & Resonance Frequency & Notch Depth \\
\hline$\varepsilon_{\mathbf{r}}$ & $\mu_{\mathbf{r}}$ & $\tan \delta_{\mathbf{e}}$ & $\tan \delta_{\mathbf{m}}$ & $\mathbf{G H z}$ & $\mathbf{d B}$ \\
\hline 1 & 1 & 0 & 0.0 & 15.17 & -39.84 \\
1 & 1 & 0 & 0.1 & 15.21 & -15.15 \\
1 & 1 & 0 & 0.2 & 15.28 & -11.06 \\
1 & 1 & 0 & 0.3 & 15.32 & -9.19 \\
1 & 1 & 0 & 0.4 & 15.30 & -8.08 \\
\hline
\end{tabular}



Figure 8. Simulated transmission coefficient $\left(\mathrm{S}_{21}\right)$ of the sensor due to interaction with the MUT with different values of magnetic loss tangent $\left(\tan \delta_{\mathrm{m}}\right)$. 


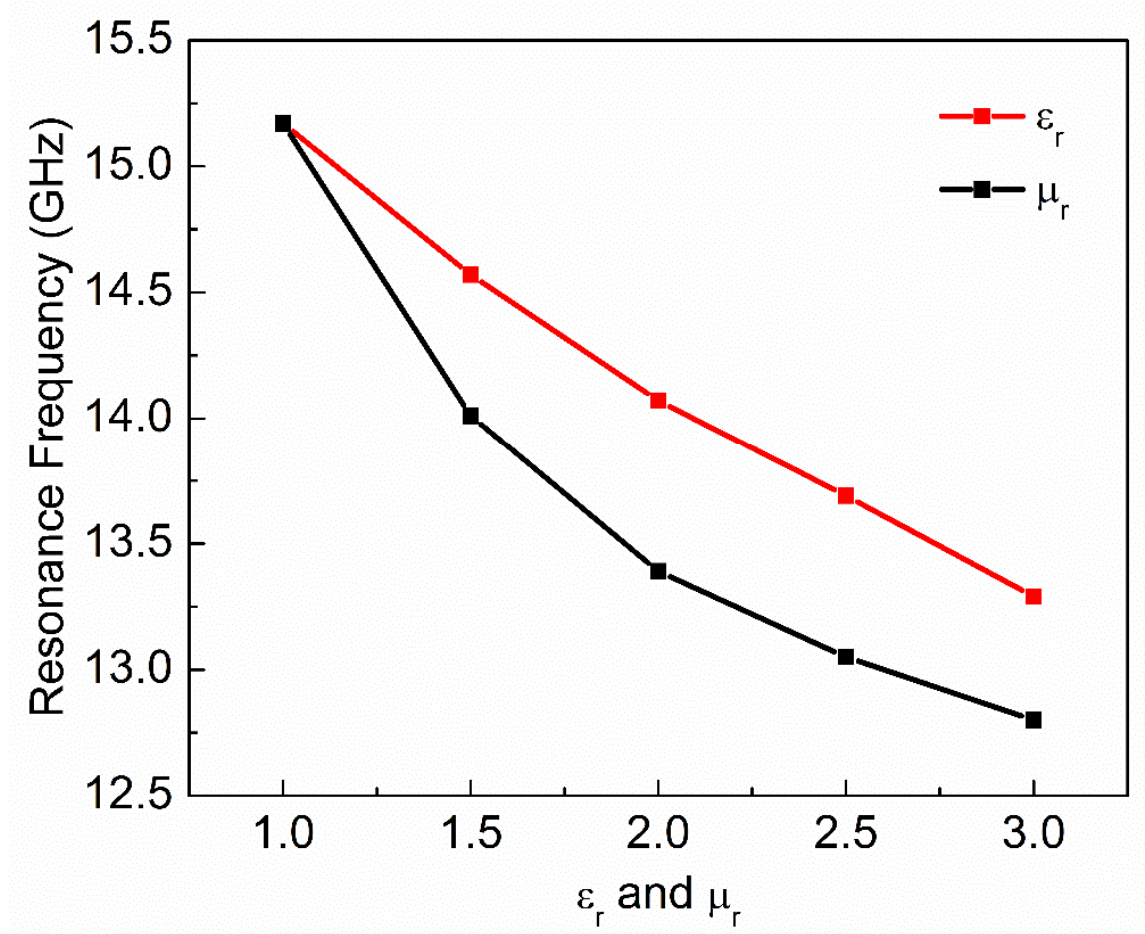

Figure 9. Real relative permittivity and permeability of MUT versus resonance frequency of the sensor.

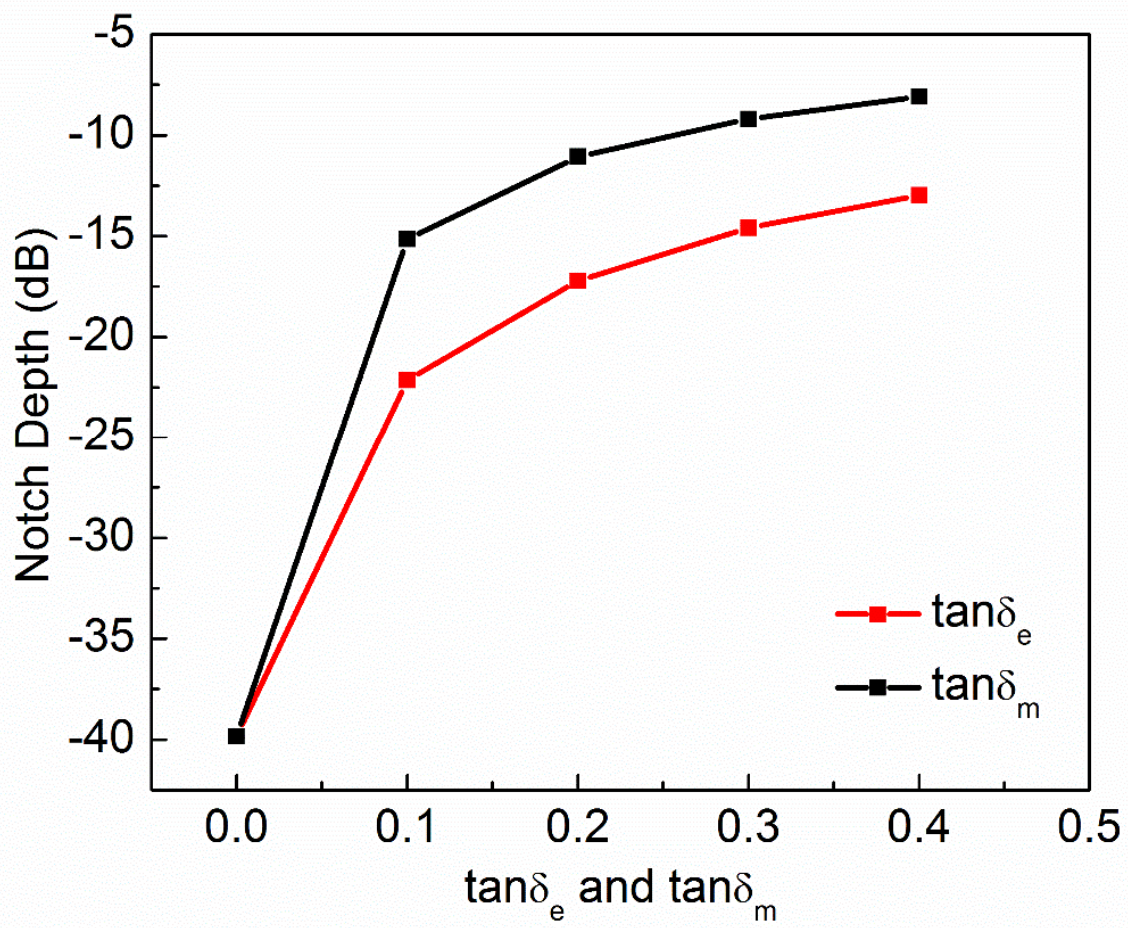

Figure 10. Dielectric loss tangent and magnetic loss tangent of MUT versus notch depth of the sensor.

\section{Measurement and Sensitivity Analysis}

The CSSSR sensor is fabricated on commercially available $1.6 \mathrm{~mm}$ FR4 substrate using the standard photolithographic technique which is simple and inexpensive. To connect the sensor with the vector network analyzer (VNA AV3672C), a pair of high-precision subminiature version A (SMA) connectors are connected at both side of microstrip transmission line. The impedance, center contact resistance and insulation resistance of the SMA connecters are $50 \Omega, \leq 0.3 \mathrm{~m} \Omega, \geq 3000 \mathrm{M} \Omega$ respectively. The 
frequency range, resolution and accuracy of VNA AV3672C are $10 \mathrm{MHz} 40 \mathrm{GHz}, 1 \mathrm{~Hz}, \pm 1 \times 10^{-7}$ respectively. The fabricated prototype of the CSSSR sensor with SMA connectors and MUT is shown in Figure 11. The VNA AV3672C is calibrated using a $2.4 \mathrm{~mm}$ calibration kit (AV31123) with frequency sweep $12 \mathrm{GHz}$ to $18 \mathrm{GHz}$, number of sweeping points 1601 and IF-bandwidth $100 \mathrm{~Hz}$. After calibration the transmission coefficient of the fabricated sensor is measured and plotted in Figure 12. The measured $f_{0}$ of the fabricated sensor is $15.12 \mathrm{GHz}$ with notch depth of $-44.33 \mathrm{~dB}$ and the unloaded quality factor is 501. The difference between simulated and measured resonance frequency, notch depth and quality factor is $0.05 \mathrm{GHz},-4.49 \mathrm{~dB}$ and 4 , respectively, which can be attributed to fabrication tolerance. To verify the sensitivity of fabricated sensor following low permittivity materials Teflon, Rogers RT5880, high density poly ethylene (HDPE) plastic, Netltec NX9240, glass polytetrafluoroethylene (PTFEreinf), polystyrene, polyvinyl chloride (PVC) plastic, Isola IS680-280, and Rubber Hard are selected. These MUTs are placed on the CSSSR and loaded resonance frequency of the sensor is calculated. Figure 13 shows the measured $S_{21}$ of the sensor due to interaction with composite MUTs.



Figure 11. Photograph of fabricated prototype of the sensor based on CSSSR with glass as MUT and high-precision SMA connectors (impedance $=50 \Omega$, center contact resistance $\leq 0.3 \mathrm{~m} \Omega$, insulation resistance $\geq 3000 \mathrm{M} \Omega$ ).

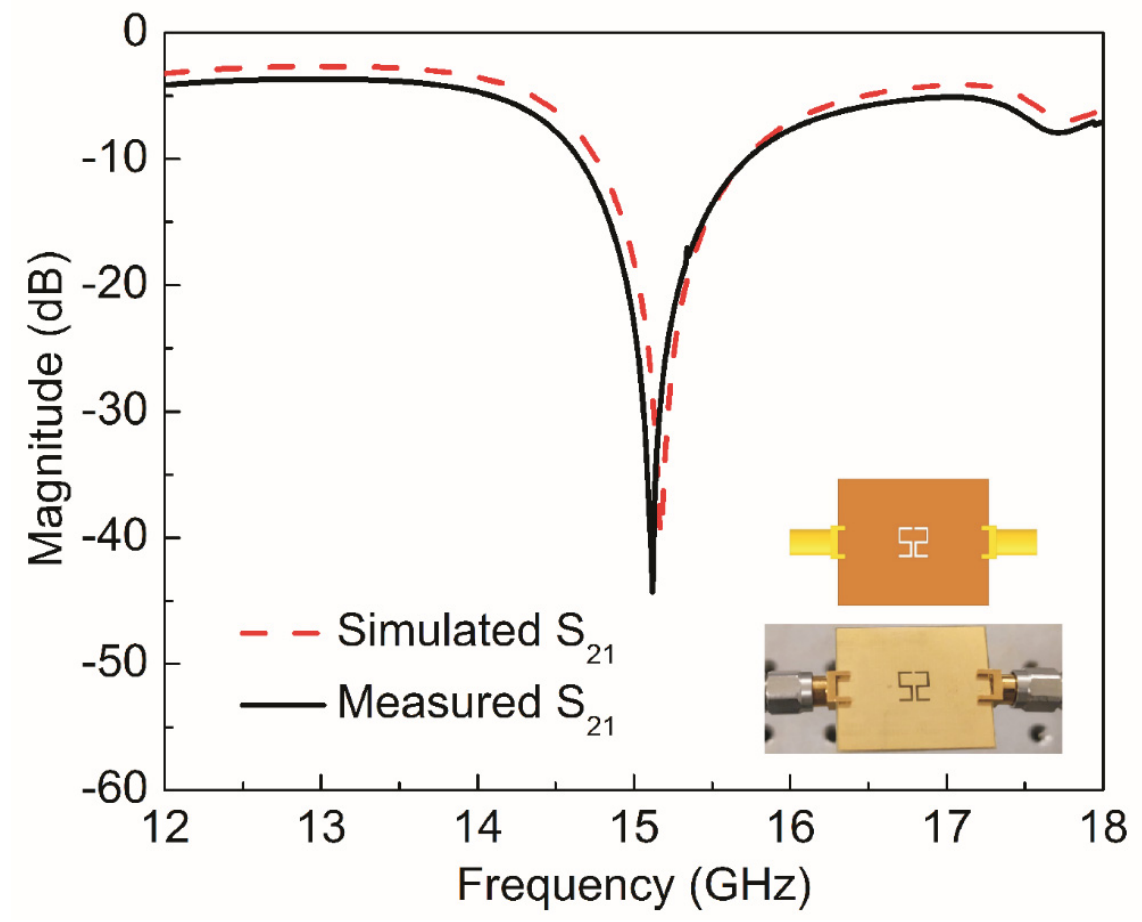

Figure 12. Magnitude of transmission $\left(S_{21}\right)$ coefficient for simulated and measured sensor based on CSSSR. Simulated resonance frequency is $15.17 \mathrm{GHz}$ with notch depth of $-39.84 \mathrm{~dB}$ while measured resonance frequency is $15.12 \mathrm{GHz}$ with notch depth of $-44.33 \mathrm{~dB}$. 


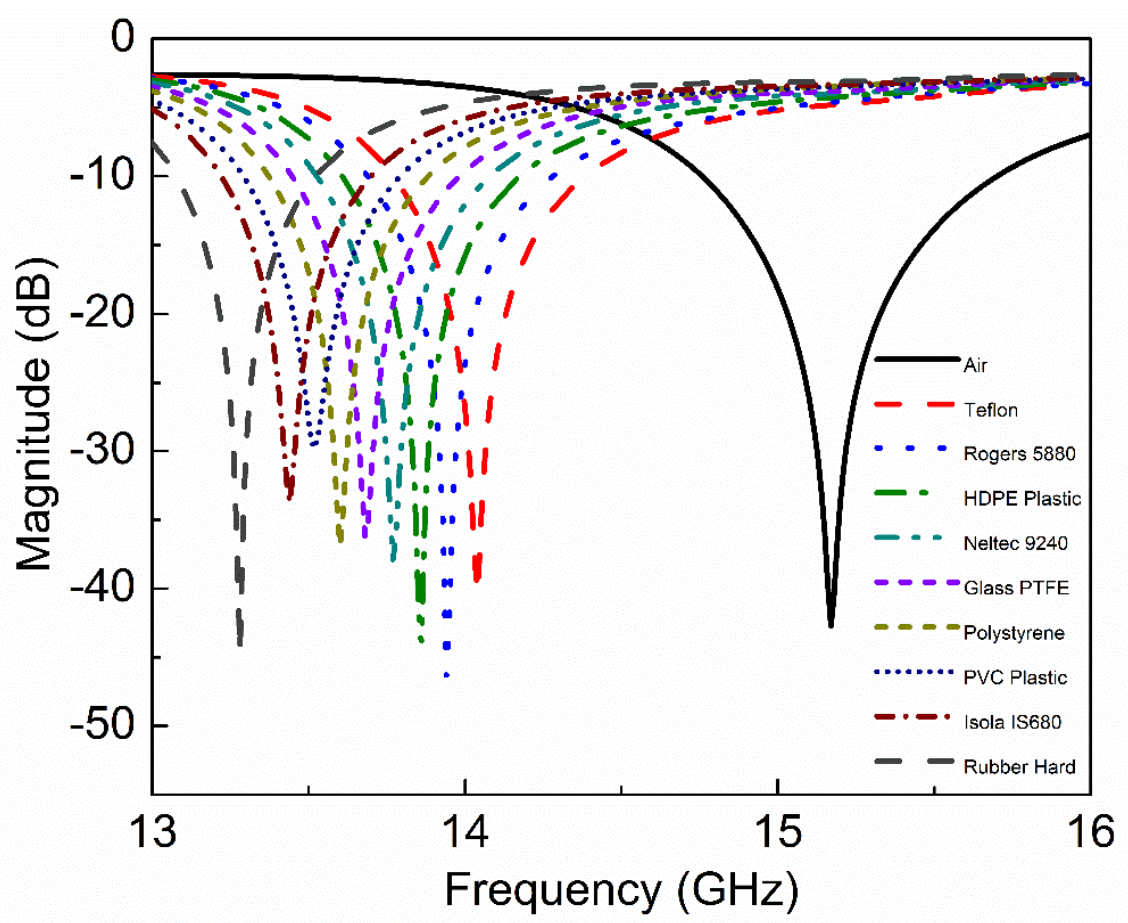

Figure 13. Measured transmission coefficient $\left(\mathrm{S}_{21}\right)$ of the sensor due to interaction with composite MUTs.

Measured $f_{0}$ of the sensors due to interaction with Teflon, Rogers RT5880, HDPE plastic, Netlec NX9240, glass PTFEreinf, polystyrene, PVC plastic, Isola IS680-280, and rubber hard are $13.99 \mathrm{GHz}$, $13.89 \mathrm{GHz}, 13.80 \mathrm{GHz}, 13.72 \mathrm{GHz}, 13.63 \mathrm{GHz}, 13.55 \mathrm{GHz}, 13.46 \mathrm{GHz}, 13.38 \mathrm{GHz}$, and $13.23 \mathrm{GHz}$ respectively. The electromagnetic properties of MUTs and loaded resonance frequency of the sensor are tabulated in Table 6. As the MUT's real permittivity is more significant than the real permeability, therefore the real relative permittivity of MUT versus simulated and measured $f_{0}$ of the sensor is plotted in Figure 14. The percentage error is $0.35 \%$ between measured and simulated resonance frequencies of the fabricated sensor when loaded with Teflon as MUT. The percentage error is $0.43 \%$ between simulated and measured resonance frequencies of the fabricated sensor when loaded with Rogers RT5880 and HDPE plastic as MUT. The percentage error is $0.36 \%$ between simulated and measured resonance frequencies of the fabricated sensor when loaded with Netltec NX9240, glass PTFEreinf and polystyrene as MUT. The percentage error is $0.44 \%$ between measured and simulated resonance frequencies of the fabricated sensor when loaded with PVC plastic and Isola IS680-280 as MUT. The percentage error is $0.37 \%$ between measured and simulated resonance frequencies of the fabricated sensor when loaded with rubber hard as MUT. The slope of Figure 14 is the sensitivity of the proposed sensor which is the ratio of differential output $\left(f_{\mathrm{d}}=f_{\mathrm{u}}-f_{1}\right)$ and differential input $\left(\varepsilon_{\mathrm{rd}}=\varepsilon_{\mathrm{r} 2}-\varepsilon_{\mathrm{r} 1}\right)$. The differential sensitivity of composite MUTs is calculated with respect to $\operatorname{Air}\left(\varepsilon_{\mathrm{r}}=1.0006\right.$, and $\left.f_{0}=15.12\right)$ and tabulated in Table 7 . The following relation is used to calculate the sensitivity of the fabricated sensor, as given in [47]:

$$
S=\frac{\partial f_{d}}{\partial \varepsilon_{r d}}=\lim _{\Delta \varepsilon_{r 2}-\Delta \varepsilon_{r 1} \rightarrow 0} \frac{\Delta f_{u}-\Delta f_{l}}{\Delta \varepsilon_{r 2}-\Delta \varepsilon_{r 1}}
$$


Table 6. Simulated and measured resonance frequencies of the sensor due to interaction with MUTs.

\begin{tabular}{|c|c|c|c|c|c|c|}
\hline \multirow{2}{*}{$\begin{array}{l}\text { Material Under Test } \\
\text { (MUT) }\end{array}$} & \multicolumn{4}{|c|}{ MUT Properties } & \multirow{2}{*}{$\begin{array}{c}\begin{array}{c}\text { Simulated } \\
\text { Resonance Frequency }\end{array} \\
\mathrm{GHz}\end{array}$} & \multirow{2}{*}{$\begin{array}{c}\text { Measured } \\
\text { Resonance Frequency } \\
\mathrm{GHz}\end{array}$} \\
\hline & $\varepsilon_{\mathrm{r}}$ & $\mu_{\mathrm{r}}$ & $\tan \delta_{e}$ & $\tan \delta_{m}$ & & \\
\hline Teflon(tm) & 2.1 & 1 & 0.001 & 0 & 14.04 & 13.99 \\
\hline Rogers RT5880 & 2.2 & 1 & 0.0009 & 0 & 13.95 & 13.89 \\
\hline HDPE Plastic & 2.3 & 1 & 0.0005 & 0 & 13.86 & 13.80 \\
\hline Neltec NX9240 & 2.4 & 1 & 0.0016 & & 13.77 & 13.72 \\
\hline Glass PTFEreinf & 2.5 & 1 & 0.002 & 0 & 13.68 & 13.63 \\
\hline Polystyrene & 2.6 & 1 & 0 & 0 & 13.60 & 13.55 \\
\hline PVC Plastic & 2.7 & 1 & 0.007 & 0 & 13.52 & 13.46 \\
\hline Isola IS680-280 & 2.8 & 1 & 0.0025 & 0 & 13.44 & 13.38 \\
\hline Rubber Hard & 3 & 1 & 0 & 0 & 13.28 & 13.23 \\
\hline
\end{tabular}



Figure 14. Real relative permittivity of MUT versus resonance frequency of the sensor. Relative permittivity of the MUT is inversely proportional to the resonance frequency of the sensor.

Table 7. Differential sensitivity of the fabricated sensor with respect to MUT.

\begin{tabular}{cccc}
\hline $\begin{array}{c}\text { Material Under Test } \\
\text { (MUT) }\end{array}$ & Differential Input & Differential Output & Differential Sensitivity \\
\hline Teflon(tm) & $\varepsilon_{M U T}-\varepsilon_{\text {Air }}$ & $f_{u}-f_{l}$ & $\%$ \\
Rogers RT5880 & 1.0994 & 1.13 & 102 \\
HDPE Plastic & 1.1994 & 1.23 & 102 \\
Netltec NX9240 & 1.2994 & 1.32 & 101 \\
Glass PTFEreinf & 1.3994 & 1.40 & 100 \\
Polystyrene & 1.4994 & 1.49 & 99 \\
PVC Plastic & 1.5994 & 1.57 & 98 \\
Isola IS680-280 & 1.6994 & 1.66 & 98 \\
Rubber Hard & 1.7994 & 1.74 & 97 \\
\hline
\end{tabular}


The relationship between the measured resonance frequencies and real relative permittivity of the MUT can be approximated by a polynomial function, as given in [64]:

$$
f_{r, M U T}=A_{1}+A_{2} \varepsilon_{r}+A_{3} \varepsilon_{r}^{2}
$$

The constant values $\left(A_{1}, A_{2}, A_{3}\right)$ of the polynomial are extracted using measured resonance frequencies $\left(f_{r, M U T}\right)$ of the sensor due to interaction with the MUT with different values of real relative permittivity $\left(\varepsilon_{r}\right)$. Finally, the transcendental equation becomes:

$$
f_{r, M U T}=16.462-1.411 \varepsilon_{r}+0.112 \varepsilon_{r}^{2}
$$

Equation (8) can predict the resonance frequency of the sensor due to interaction with an MUT with real relative permittivity ranges from 2.1 to 3 . Equation (8) can be rearranged to calculate relative permittivity in the following form:

$$
\varepsilon^{\prime}{ }_{r}=\frac{1.411-\sqrt{1.99-0.448\left(16.462-f_{r, M U T}\right)}}{0.224}
$$

Equation (9) can be used to calculate the relative permittivity of an unknown MUT by measuring the resonance frequency of the sensor due to interaction with the unknown MUT. The relative sensitivity is most important parameter to compare the performance of with other sensors. The relative sensitivity of the microwave sensor based on permittivity perturbation is defined as [65]:

$$
S_{\varepsilon_{r}}=\frac{f_{r, M U T}-f_{0}}{f_{0}\left(\varepsilon_{r}-1\right)} \times 100
$$

where $f_{r, M U T}$ is the resonance frequency of the sensor due to interaction with the MUT with relative permittivity $\varepsilon_{\mathrm{r}}$. The relative sensitivity of various state of the art sensors [66-70] is tabulated in Table 8 .

Table 8. Comparison of relative sensitivity with various state of the art sensors.

\begin{tabular}{ccccc}
\hline Ref & $\begin{array}{c}\text { Resonating } \\
\text { Structure }\end{array}$ & $\begin{array}{c}\text { Resonance Frequency } \\
\text { (GHz) }\end{array}$ & $\begin{array}{c}\text { Permittivity } \\
\text { Range Studied }\end{array}$ & $\begin{array}{c}\text { Relative Sensitivity } \\
\text { (\%) }\end{array}$ \\
\hline$[65]$ & SIR & 1.91 & $10-80$ & 0.84 \\
{$[66]$} & CSRR & 2.4 & $10-80$ & 0.61 \\
{$[67]$} & SRR & 1.72 & $10-80$ & 0.78 \\
{$[68]$} & Open-Loop & 2.6 & $10-140$ & 1.49 \\
{$[69]$} & Resonators & 1.8 & $2.42-22.52$ & 3.04 \\
{$[70]$} & SRR & 2.5 & $2.93-3.64$ & 3.58 \\
This Work & CSRR & 15.12 & $2.1-3$ & 6.7 \\
\hline
\end{tabular}

\section{Conclusions}

This paper presents an extremely sensitive microwave sensor that is based on a microstrip transmission line and complementary symmetric $S$ shape resonator (CSSSR) to measure the relative permittivity of low permittivity materials. The proposed sensor is sensitive for the four parameters of $\operatorname{MUT}\left(\varepsilon_{r}, \mu_{r}, \tan \delta_{e}, \tan \delta_{m}\right)$ which is demonstrated by electromagnetic simulation. It is concluded that the fringing electromagnetic fields of CSSSR interact with the MUT, and real relative permittivity and permeability which are greater than unity cause a decrease in the resonance frequency while dielectric and magnetic loss tangents cause a decrease in the magnitude of the transmission coefficient. After fabrication, the fabricated sensor is used to measure composite MUTs and relative sensitivity of $6.7 \%$ is achieved with a measurement error less than $0.5 \%$. The transcendental equation for the CSSSR sensor is derived by approximating the resonance frequencies of the sensor with respect to the relative permittivity of composite MUTs. 
Author Contributions: T.H. proposed the structure of the sensor, simulated and fabricated and used the device to test different dielectric substrates and the method to achieve it, participated in conducting experiments and recording the data, cataloged references and analyzed the measured results, and prepared the whole manuscript. C.R. is the research head of the experiment, proposed the design and experimental idea, analyzed the data, and participated in the revision of the paper. X.Z., S.U., A.K.F. and W.H. participated in the experiment and recorded the data, and participated in the preparation of the manuscript. All authors have read and agreed to the published version of the manuscript.

Funding: This research was funded by National Natural Science Foundation of China, grant number 61831001, the High-Level Talent Introduction Project of Beihang University, grant number ZG216S1878and the Youth-Top-Talent Support Project of Beihang University, grant number ZG226S1821.

Conflicts of Interest: The authors declare no conflict of interest.

\section{References}

1. Trabelsi, S.; Nelson, S.O. Microwave sensing of quality attributes of agricultural and food products. IEEE Instrum. Meas. Mag. 2016, 19, 36-41. [CrossRef]

2. Wagner, N.; Emmerich, K.; Bonitz, F.; Kupfer, K. Experimental Investigations on the Frequency-and Material Properties of Soil. IEEE Trans. Geosci. Remote Sens. 2011, 49, 2518-2530. [CrossRef]

3. Puentes, M.; Maasch, M.; Schubler, M.; Jakoby, R. Frequency multiplexed 2-dimensional sensor array based on split-ring resonators for organic tissue analysis. IEEE Trans. Microw. Theory Tech. 2012, 60, 1720-1727. [CrossRef]

4. RoyChoudhury, S.; Rawat, V.; Jalal, A.H.; Kale, S.N.; Bhansali, S. Recent advances in metamaterial split-ring-resonator circuits as biosensors and therapeutic agents. Biosens. Bioelectron. 2016, 86, 595-608. [CrossRef] [PubMed]

5. Lee, H.J.; Lee, J.H.; Moon, H.S.; Jang, I.S.; Choi, J.S.; Yook, J.G.; Jung, H.I. A planar split-ring resonator-based microwave biosensor for label-free detection of biomolecules. Sensors Actuators, B Chem. 2012, 169, $26-31$. [CrossRef]

6. Zarifi, M.H.; Sadabadi, H.; Hejazi, S.H.; Daneshmand, M.; Sanati-Nezhad, A. Noncontact and Nonintrusive Microwave-Microfluidic Flow Sensor for Energy and Biomedical Engineering. Sci. Rep. 2018, 8, 1-10. [CrossRef]

7. Schueler, M.; Mandel, C.; Puentes, M.; Jakoby, R. Metamaterial inspired microwave sensors. IEEE Microw. Mag. 2012, 13, 57-68. [CrossRef]

8. Abdolrazzaghi, M.; Zarifi, M.H.; Pedrycz, W.; Daneshmand, M. Robust Ultra-High Resolution Microwave Planar Sensor Using Fuzzy Neural Network Approach. IEEE Sens. J. 2017, 17, 323-332. [CrossRef]

9. Zarifi, M.H.; Deif, S.; Abdolrazzaghi, M.; Chen, B.; Ramsawak, D.; Amyotte, M.; Vahabisani, N.; Hashisho, Z.; Chen, W.; Daneshmand, M. A microwave ring resonator sensor for early detection of breaches in pipeline coatings. IEEE Trans. Ind. Electron. 2017, 65, 1626-1635. [CrossRef]

10. Zarifi, M.H.; Daneshmand, M. Monitoring Solid Particle Deposition in Lossy Medium Using Planar Resonator Sensor. IEEE Sens. J. 2017, 17, 7981-7989. [CrossRef]

11. Kumari, R.; Patel, P.N.; Yadav, R. An ENG-Inspired Microwave Sensor and Functional Technique for Label-Free Detection. IEEE Sens. J. 2018, 18, 3932-3939. [CrossRef]

12. Machac, J. Amorphous Metamaterial with Negative Permeability. IEEE Antennas Wirel. Propag. Lett. 2017, 16, 2138-2141. [CrossRef]

13. Shelby, R.A.; Smith, D.R.; Schultz, S. Experimental verification of a negative index of refraction. Science 2001, 292, 77-79. [CrossRef] [PubMed]

14. Ji, L.; Varadan, V.V. Negative refractive index and negative refraction of waves in lossy metamaterials. Electron. Lett. 2016, 52, 260-262. [CrossRef]

15. Isik, O.; Esselle, K.P. Backward wave microstrip lines with complementary spiral resonators. IEEE Trans. Antennas Propag. 2008, 56, 3173-3178. [CrossRef]

16. Pendry, J.B.; Holden, A.J.; Robbins, D.J.; Stewart, W.J. Magnetism from conductors and enhanced nonlinear phenomena. IEEE Trans. Microw. Theory Tech. 1999, 47, 2075-2084. [CrossRef]

17. Falcone, F.; Lopetegi, T.; Baena, J.D.; Marqués, R.; Martín, F.; Sorolla, M. Effective negative- $\varepsilon$ stopband microstrip lines based on complementary split ring resonators. IEEE Microw. Wirel. Components Lett. 2004, 14, 280-282. [CrossRef] 
18. Withayachumnankul, W.; Jaruwongrungsee, K.; Tuantranont, A.; Fumeaux, C.; Abbott, D. Metamaterial-based microfluidic sensor for dielectric characterization. Sensors Actuators, A Phys. 2013, 189, 233-237. [CrossRef]

19. Abdolrazzaghi, M.; Zarifi, M.H.; Daneshmand, M. Sensitivity enhancement of split ring resonator based liquid sensors. Proc. IEEE Sensors 2017, 5-7. [CrossRef]

20. Chuma, E.L.; Iano, Y.; Fontgalland, G.; Bravo Roger, L.L. Microwave sensor for liquid dielectric characterization based on metamaterial complementary split ring resonator. IEEE Sens. J. 2018, 18, 9978-9983. [CrossRef]

21. Mohd Bahar, A.A.; Zakaria, Z.; Ab Rashid, S.R.; Isa, A.A.M.; Alahnomi, R.A. High-efficiency microwave planar resonator sensor based on bridge split ring topology. IEEE Microw. Wirel. Components Lett. 2017, 27, 545-547. [CrossRef]

22. Zhang, X.; Ruan, C.; Ul Haq, T.; Chen, K. High-sensitivity microwave sensor for liquid characterization using a complementary circular spiral resonator. Sensors 2019, 19, 787. [CrossRef] [PubMed]

23. Boybay, M.S.; Ramahi, O.M. Non-destructive thickness measurement using quasi-static resonators. IEEE Microw. Wirel. Components Lett. 2013, 23, 217-219. [CrossRef]

24. Lee, C.S.; Yang, C.L. Thickness and permittivity measurement in multi-layered dielectric structures using complementary split-ring resonators. IEEE Sens. J. 2014, 14, 695-700. [CrossRef]

25. Lee, C.S.; Yang, C.L. Single compound complementary split-ring resonator for simultaneously measuring permittivity and thickness. IEEE MTT-S Int. Microw. Symp. Dig. 2014, 1-3. [CrossRef]

26. Yang, C.L.; Lee, C.S.; Chen, K.W.; Chen, K.Z. Noncontact measurement of complex permittivity and thickness by using planar resonators. IEEE Trans. Microw. Theory Tech. 2016, 64, 247-257. [CrossRef]

27. Abdolrazzaghi, M.; Khan, S.; Daneshmand, M. A Dual-Mode Split-Ring Resonator to Eliminate Relative Humidity Impact. IEEE Microw. Wirel. Components Lett. 2018, 28, 939-941. [CrossRef]

28. Naqui, J.; Durán-Sindreu, M.; Martín, F. Novel sensors based on the symmetry properties of split ring resonators (SRRs). Sensors 2011, 11, 7545-7553. [CrossRef]

29. Naqui, J.; Durán-Sindreu, M.; Martín, F. Alignment and position sensors based on split ring resonators. Sensors 2012, 12, 11790-11797. [CrossRef]

30. Horestani, A.K.; Fumeaux, C.; Al-Sarawi, S.F.; Abbott, D. Displacement sensor based on diamond-shaped tapered split ring resonator. IEEE Sens. J. 2013, 13, 1153-1160. [CrossRef]

31. Horestani, A.K.; Naqui, J.; Shaterian, Z.; Abbott, D.; Fumeaux, C.; Martín, F. Two-dimensional alignment and displacement sensor based on movable broadside-coupled split ring resonators. Sensors Actuators, A Phys. 2014, 210, 18-24.

32. Horestani, A.K.; Naqui, J.; Abbott, D.; Fumeaux, C.; Martín, F. Two-dimensional displacement and alignment sensor based on reflection coefficients of open microstrip lines loaded with split ring resonators. Electron. Lett. 2014, 50, 620-622. [CrossRef]

33. Naqui, J.; Martin, F. Transmission lines loaded with bisymmetric resonators and their application to angular displacement and velocity sensors. IEEE Trans. Microw. Theory Tech. 2013, 61, 4700-4713. [CrossRef]

34. Horestani, A.K.; Abbott, D.; Fumeaux, C. Rotation sensor based on horn-shaped split ring resonator. IEEE Sens. J. 2013, 13, 3014-3015. [CrossRef]

35. Ebrahimi, A.; Withayachumnankul, W.; Al-Sarawi, S.F.; Abbott, D. Metamaterial-inspired rotation sensor with wide dynamic range. IEEE Sens. J. 2014, 14, 2609-2614. [CrossRef]

36. Mata-Contreras, J.; Herrojo, C.; Martin, F. Application of Split Ring Resonator (SRR) Loaded Transmission Lines to the Design of Angular Displacement and Velocity Sensors for Space Applications. IEEE Trans. Microw. Theory Tech. 2017, 65, 4450-4460. [CrossRef]

37. Melik, R.; Unal, E.; Perkgoz, N.K.; Puttlitz, C.; Demir, H.V. Metamaterial-based wireless strain sensors. Appl. Phys. Lett. 2009, 95, 1-3. [CrossRef]

38. Hasani, M.; Vena, A.; Sydanheimo, L.; Ukkonen, L.; Tentzeris, M.M. Implementation of a dual-interrogation-mode embroidered RFID-Enabled strain sensor. IEEE Antennas Wirel. Propag. Lett. 2013, 12, 1272-1275. [CrossRef]

39. Thai, T.T.; Aubert, H.; Pons, P.; Dejean, G.; Mtentzeris, M.; Plana, R. Novel design of a highly sensitive RF strain transducer for passive and remote sensing in two dimensions. IEEE Trans. Microw. Theory Tech. 2013, 61, 1385-1396. [CrossRef]

40. Muhammed Shafi, K.T.; Ansari, M.A.H.; Jha, A.K.; Akhtar, M.J. Design of SRR-based microwave sensor for characterization of magnetodielectric substrates. IEEE Microw. Wirel. Components Lett. 2017, 27, 524-526. 
41. Muhammed Shafi, K.T.; Jha, A.K.; Akhtar, M.J. Improved Planar Resonant RF Sensor for Retrieval of Permittivity and Permeability of Materials. IEEE Sens. J. 2017, 17, 5479-5486. [CrossRef]

42. Saadat-safa, M.; Nayyeri, V.; Member, S.; Khanjarian, M.; Soleimani, M.; Ramahi, O.M. A CSRR-Based Sensor for Full Characterization of Magneto-Dielectric Materials. IEEE Trans. Microw. Theory Tech. 2019, 67, 806-814. [CrossRef]

43. Velez, P.; Su, L.; Grenier, K.; Mata-Contreras, J.; Dubuc, D.; Martin, F. Microwave Microfluidic Sensor Based on a Microstrip Splitter/Combiner Configuration and Split Ring Resonators (SRRs) for Dielectric Characterization of Liquids. IEEE Sens. J. 2017, 17, 6589-6598. [CrossRef]

44. Su, L.; Mata-Contreras, J.; Vélez, P.; Martín, F. Configurations of splitter/combiner microstrip sections loaded with stepped impedance resonators (SIRs) for sensing applications. Sensors 2016, 16, 2195. [CrossRef] [PubMed]

45. Su, L.; Mata-Contreras, J.; Velez, P.; Martin, F. Splitter/combiner microstrip sections loaded with pairs of Complementary Split Ring Resonators (CSRRs): Modeling and optimization for differential sensing applications. IEEE Trans. Microw. Theory Tech. 2016, 64, 4362-4370. [CrossRef]

46. Ebrahimi, A.; Scott, J.; Ghorbani, K. Differential sensors using microstrip lines loaded with two split-ring resonators. IEEE Sens. J. 2018, 18, 5786-5793. [CrossRef]

47. Naqui, J.; Damm, C.; Wiens, A.; Jakoby, R.; Su, L.; Mata-Contreras, J.; Martín, F. Transmission Lines Loaded With Pairs of Stepped Impedance Resonators: Modeling and Application to Differential Permittivity Measurements. IEEE Trans. Microw. Theory Tech. 2016, 64, 3864-3877. [CrossRef]

48. Haq, T.; Ruan, C.; Ullah, S.; Kosar Fahad, A. Dual notch microwave sensors based on complementary metamaterial resonators. IEEE Access 2019, 7, 153489-153498. [CrossRef]

49. Boybay, M.S.; Ramahi, O.M. Material characterization using complementary split-ring resonators. IEEE Trans. Instrum. Meas. 2012, 61, 3039-3046. [CrossRef]

50. Lee, C.S.; Yang, C.L. Complementary split-ring resonators for measuring dielectric constants and loss tangents. IEEE Microw. Wirel. Components Lett. 2014, 24, 563-565. [CrossRef]

51. Lee, C.S.; Yang, C.L. Single-compound complementary split-ring resonator for simultaneously measuring the permittivity and thickness of dual-layer dielectric materials. IEEE Trans. Microw. Theory Tech. 2015, 63, 2010-2023. [CrossRef]

52. Ansari, M.A.H.; Jha, A.K.; Akhtar, M.J. Design and Application of the CSRR-Based Planar Sensor for Noninvasive Measurement of Complex Permittivity. IEEE Sens. J. 2015, 15, 7181-7189. [CrossRef]

53. Florencio Díaz, R.; Rodríguez Boix, R.; Carrasco Yépez, F.; Encinar Garcinuño, J.; Barba Gea, M.; Pérez Palomino, G. Broadband reflectarrays made of cells with three coplanar parallel dipoles. Microw. Opt. Technol. Lett. 2014, 56, 748-753. [CrossRef]

54. Alotaibi, S.A.; Cui, Y.; Tentzeris, M.M. CSRR Based Sensors for Relative Permittivity Measurement with Improved and Uniform Sensitivity throughout [0.9-10.9] GHz Band. IEEE Sens. J. 2019, 1-12. [CrossRef]

55. Langlois, S.; Lit, J.W.Y. S-resonator with an end reflector. J. Light. Technol. 1999, 17, 1487-1492. [CrossRef]

56. Deleniv, A.; Gashinova, M.; Eriksson, A.; Khalabuhov, A. Novel band-pass filter utilizing S-shaped slot line resonators. IEEE MTT-S Int. Microw. Symp. Dig. 2003, 2, 1081-1084.

57. Chen, F.C.; Chu, Q.X. A compact dual-band filter using S-shaped stepped impedance resonators. 2008 Int. Conf. Microw. Millim. Wave Technol. Proceedings, ICMMT 2008, 3, 1255-1257.

58. Suntheralingam, N.; Budimir, D. Compact S-shaped resonator loaded waveguide bandpass filters. IEEE Antennas Propag. Soc. AP-S Int. Symp. 2009, 1-4.

59. Khan, M.F.; Mughal, M.J. Tunable metamaterials by varying the inductance and capacitance of S-shaped resonator. In Proceedings of the 20093rd IEEE International Symposium on Microwave, Antenna, Propagation and EMC Technologies for Wireless Communications, Beijing, China, 27-29 October 2009; pp. 140-143.

60. Herrojo, C.; Mata-Contreras, J.; Paredes, F.; Martín, F. Microwave Encoders for Chipless RFID and Angular Velocity Sensors Based on S-Shaped Split Ring Resonators. IEEE Sens. J. 2017, 17, 4805-4813. [CrossRef]

61. Bonache, J.; Gil, M.; Gil, I.; García-García, J.; Martín, F. On the electrical characteristics of complementary metamaterial resonators. IEEE Microw. Wirel. Components Lett. 2006, 16, 543-545. [CrossRef]

62. Haq, T.; Ruan, C.; Zhang, X.; Kosar, A.; Ullah, S. Low cost and compact wideband microwave notch filter based on miniaturized complementary metaresonator. Appl. Phys. A Mater. Sci. Process. 2019, 125, 1-7. [CrossRef]

63. Pozar, D.M. Microwave Engineering; John Wiley \& Sons, Inc.: Hoboken, NJ, USA, 2012; ISBN 9789896540821. 
64. Haq, T.U.; Ruan, C.; Zhang, X.; Ullah, S. Complementary Metamaterial Sensor for Nondestructive Evaluation of Dielectric Substrates. Sensors 2019, 19, 2100. [CrossRef] [PubMed]

65. Ebrahimi, A.; Scott, J.; Ghorbani, K. Ultrahigh-Sensitivity Microwave Sensor for Microfluidic Complex Permittivity Measurement. IEEE Trans. Microw. Theory Tech. 2019, 67, 4269-4277. [CrossRef]

66. Ebrahimi, A.; Withayachumnankul, W.; Al-Sarawi, S.; Aboott, D. High-Sensitivity Metamaterial-Inspired Sensor. IEEE Sens. J. 2014, 14, 1345-1351. [CrossRef]

67. Rowe, D.J.; Abduljabar, A.A.; Porch, A.; Barrow, D.A.; Allender, C.J. Improved Split-Ring Resonator for Micro Fluidic Sensing. IEEE Trans. Microw. Theory Tech. 2014, 62, 689-700. [CrossRef]

68. Abdolrazzaghi, M.; Daneshmand, M.; Iyer, A.K. Strongly Enhanced Sensitivity in Planar Microwave Sensors Based on Metamaterial Coupling. IEEE Trans. Microw. Theory Tech. 2018, 66, 1843-1855. [CrossRef]

69. Galindo-Romera, G.; Javier Herraiz-Martínez, F.; Gil, M.; Martínez-Martínez, J.J.; Segovia-Vargas, D. Submersible Printed Split-Ring Resonator-Based Sensor for Thin-Film Detection and Permittivity Characterization. IEEE Sens. J. 2016, 16, 3587-3596. [CrossRef]

70. Su, L.; Mata-Contreras, J.; Vélez, P.; Fernández-Prieto, A.; Martín, F. Analytical method to estimate the complex permittivity of oil samples. Sensors 2018, 18, 984. [CrossRef]

(C) 2020 by the authors. Licensee MDPI, Basel, Switzerland. This article is an open access article distributed under the terms and conditions of the Creative Commons Attribution (CC BY) license (http://creativecommons.org/licenses/by/4.0/). 